\title{
Group Payoffs As Public Signals
}

\author{
Christos A. Ioannou ${ }^{* \dagger}$ \\ Shi Qi $\ddagger$ \\ Aldo Rustichini § \\ University of Southampton \\ Florida State University \\ University of Minnesota
}

This draft: March 2, 2015

\begin{abstract}
We study experimentally the effect on individual behavior of comparative, but payoff-irrelevant, information in a near-minimal group setting. Specifically, in each round, group members see the groups' cumulative payoffs, which consist of an aggregation of the earnings of each member of the group in the round. Our novel experimental design incorporates two games (the Trust game and the Dictator game) whose payoffs are carefully chosen to ensure cross-game comparability. In the baseline, no comparative information is displayed; the sessions are otherwise identical.

Our first set of results shows that the display is sufficient to induce an in-group bias, which can neither be attributed to mere categorization of subjects into groups nor to a stronger sense of group identity as a result of the display. Moreover, we corroborate existing results, which find that, relative to the baseline, the display is welfare reducing in the Trust game. Our second set of results shows that when comparing the allocators' decisions across the two games, a first mover's trust is reciprocated by the second mover independently of group identity.
\end{abstract}

JEL: C51, C92, C72, D03

Keywords: Trust Game, Dictator Game, Group Identity, Public Signals

${ }^{*}$ The paper has benefited greatly from the comments of Sherry Xin Li, David J. Cooper, Tim Salmon, Miltos Makris, Alice Schoonbroodt and Mirco Tonin. We would, also, like to thank the seminar participants at the Florida State University, University of Southampton, University of St Andrews, International Meeting on Experimental and Behavioral Economics (April 2011), North American Summer Meetings (June 2011) and Royal Economic Society Conference (April 2012). Finally, we are indebted to the editor, Martin Kocher, and two anonymous referees for their detailed and helpful comments, which significantly improved the paper. The research was supported, in part, by research funds from the Florida State University, the Strategic Research Development Fund of the University of Southampton and the British Academy (under grant number SG110905 to Christos A. Ioannou). The usual disclaimer applies.

${ }^{\dagger}$ (Corresponding Author) Mailing Address: Department of Economics, University of Southampton, Southampton, SO17 1BJ, United Kingdom. Email: c.ioannou@soton.ac.uk

${ }_{\ddagger}^{\ddagger}$ Mailing Address: Department of Economics, Florida State University, 113 Collegiate Loop, Bellamy 288, Tallahassee, FL 32306. Email: sqi@fsu.edu

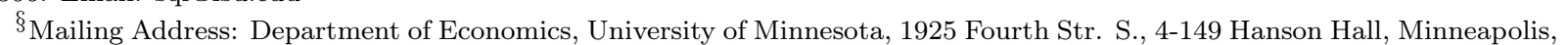
MN 55455. Email: arust@econ.umn.edu 


\section{Introduction}

Recent experimental literature has shown that information on groups' performance promotes intergroup competition, which, in turn, induces improved group cooperation (e.g. Bornstein, Erev, and Rosen (1990), Erev, Bornstein, and Galili (1993), Erev and Bornstein (1994), Nalbantian and Schotter (1997), Bornstein, Gneezy, and Nagel (2002), Eckel and Grossman (2005)). This research has been noticeably restricted to payment schemes where group members' payoffs are contingent on the group's performance relative to that of the other group(s). In light of the relatively recent (but not group-based) literature on the impact of social comparison on decision making, ${ }^{1}$ it is, thus, not clear whether the improved group cooperation is an outcome of the payoff consequences or the comparative information provided.

Our primary objective in this study is to determine experimentally the effect on individual behavior of comparative, but payoff-irrelevant, information in a near-minimal group setting. ${ }^{2}$ More specifically, we investigate whether the display of comparative information is sufficient to invoke behavioral differences across in-group and out-group members. We, also, examine the implications of the display on participants' group attachment and welfare. To determine the effect of the display per se, we establish a baseline where no comparative information is displayed; this enables us to, also, test whether, as Social Identity Theory postulates, mere categorization of subjects into groups is sufficient to lead to behavioral differences across in-group and out-group members (Tajfel and Turner (1986)). ${ }^{3}$ An additional virtue of our framework is that it utilizes two games (the Trust game and the Dictator game), which allow us to determine the sensitivity of our main hypothesis to the nature of the game. Crucially, the payoffs are identical for the specific choices made across the two games (see, Subsection 2.2 for more details); otherwise, a change in behavior could be attributed to a change in the monetary incentives. Thus, a secondary objective in this study is to investigate

\footnotetext{
${ }^{1}$ Studies differ in the type of social information selected and presented to participants. Several studies present the decisions of other participants (e.g. Cason and Mui (1998), Duffy and Feltovich (1999), Eckel and Wilson (2007), Krupka and Weber (2009), Shang and Croson (2009)). Some studies present a statistic on the participants' offer/contribution/rating (Bohnet and Zeckhauser (2004), Frey and Meier (2004), Chen, Harper, Konstan, and $\mathrm{Li}(2010)$ ). Finally, another set of studies presents the complete ranking of all participants (e.g. Duffy and Kornienko (2010)).

${ }^{2}$ A near-minimal group setting is one with (a) a trivial group assignment, (b) no social interaction, and (c) anonymity. Groups are considered minimal if, in addition to these three conditions, the condition that there is no trade-off between the decision-maker's payoff and others' payoffs is also satisfied.

${ }^{3}$ The Social Identity Theory argues that individuals have a desire for positive self-identity. This positive image may derive, in part, from one's own qualities, but, also, from membership to one's group. In this latter case, a positive image of the group induces a positive image of the individual member. Esteem for one's group may be positive or negative depending on how well the in-group members compare to relevant out-groups. Thus, in-group members gain if the comparison with other groups is more favorable because their self-image improves.
} 
any behavioral differences when the allocator (the second mover in the Trust game or the dictator in the Dictator game) decides on the split. ${ }^{4}$ To the best of our knowledge, this is the first study to address the role of trust and reciprocity in a group setting via cross-game comparisons.

Our experimental design consists of three stages. In the first stage, participants are divided equally into two groups on the basis of a trivial criterion. In the second stage, participants play either the Dictator game or the Trust game. ${ }^{5}$ In the last stage, participants complete a questionnaire, which consists of explicit statements to measure their group attachment and some questions of demographic nature. An important design decision is the type of social information provided in the experiment. Based on the findings in other studies and our choice of games, we choose to display the groups' cumulative payoffs in the round; the latter consist of an aggregation of the earnings of each member of the group in the round (henceforth, for brevity, referred to as group payoffs unless there is a risk of confusion) ${ }^{6}$ It is important to note that our design is symmetric in that groups' payoffs consist of an equal number of subjects with equivalent roles round after round; that is, there are as many second movers/dictators in one group as there are in the other group in any given round. Crucially, the display of group payoffs has no effect on agents' earnings, but provides information on other players' behavior albeit in different ways. In the Dictator game, an endowment $\tilde{x}$ to be allocated by a dictator to an in-group member will increase the group's payoffs by $\tilde{x}$ regardless of the allocation; thus, no information is revealed on the generosity between in-group members. However, when a dictator allocates an amount to an out-group member, then, information is revealed on the generosity to out-group members as the payoffs of both groups are affected. Conversely, the display of group payoffs in the Trust game provides information on, both, the generosity between in-group members and the generosity to out-group members. On one hand, larger generosity of first movers to in-group second movers unambiguously increases the payoff of the group because of the multiplier on the initial transfer. The decision of the second mover, in this case, is of no consequence to the group's payoffs. On the other hand, any generosity to out-group first movers unambiguously

\footnotetext{
${ }^{4}$ The role of the dictator in the Dictator game and the second mover in the Trust game are somewhat similar in the sense that they are the ones to allocate the final payoffs. Although, as an anonymous referee points out, the two decisions clearly differ for the possible reciprocation in one and not in the other.

${ }^{5} \mathrm{~A}$ value added of using the Trust game is its connection to the work on social capital. However, in sharp contrast to the studies, mostly, on the Public Goods game that investigate behavioral changes in a setting with a single group, here, we report decisions in a setting with two groups.

${ }^{6}$ The type of information provided is a rather subtle issue in the sense that it could make an outcome focal. A large body of literature in social psychology (some cited above) shows that social comparisons affect behavior since individuals gain information on what constitutes the 'right behavior' in various contexts. We believe that the display of groups' payoffs relative to another statistic, such as an average or a median, provides some pertinent information on group behavior, without making an outcome prominent.
} 
reduces the group's payoffs.

Our first set of results demonstrates that the display of group payoffs is sufficient to invoke an in-group bias in both games (i.e. a link between the group members' payoffs and the group's behavior relative to that of the other group is not a necessary condition for an in-group bias). We say there is an in-group bias if the payoff of an allocator who is matched with an out-group member is significantly different (larger) than the allocator's payoff when matched with an in-group member. We investigate why the display of group payoffs has this effect on behavior. We find that the in-group bias can neither be attributed to mere categorization of subjects into groups nor to a stronger sense of group identity as a result of the display. We propose instead that the display of group payoffs acts as a public signal that makes groups salient, and this, in turn, produces the in-group bias; however, we defer testing this conjecture for future research. Moreover, motivated by the study of Hargreaves Heap and Zizzo (2009), we investigate the welfare implications of the display of group payoffs in the Trust game. ${ }^{7}$ In contrast to our study, Hargreaves Heap and Zizzo (2009) provide subjects with explicit information on the average giving rates and average return rates of in-group and out-group members. Relative to a baseline without group assignment, they find that "the existence of groups ... tangibly reduces trust in the aggregate, and thus is welfare reducing" (p. 297). Similar to the aforementioned study, we, also, find that, relative to the baseline, total welfare goes down when group payoffs are displayed: first movers transfer significantly less to out-group second movers and do not transfer significantly more to in-group second movers.

Our second set of results comes from conducting cross-game comparisons to determine any behavioral differences when the allocator decides on the split. Existing literature (see, for instance, Berg, Dickhaut, and McCabe (1995)) demonstrates that agents are concerned not, only, with the distribution of the material payoff, but, also, with the process leading up to the available choices. Controlling for the level of transfer/endowment and group identity, when comparing the allocators' decisions across the two games, we find that second movers 'return' to first movers significantly more compared to what dictators give to passive participants (i.e. a first mover's trust is reciprocated by the second mover regardless of the first mover's identity). We, also, find that the extent of reciprocation depends on the identity of the first mover, only, when group payoffs are displayed; that is, in the baseline, second movers make statistically similar 'returns' regardless of the first mover's identity.

The rest of the paper is organized as follows. In Section 2, we provide the experimental design. In Section 3, we report the main findings, and, finally, in Section 4, we summarize

\footnotetext{
${ }^{7}$ The Dictator game is not suitable for welfare analysis as the total number of quarters in the game play is fixed ex ante by the experimenter.
} 
our results, and offer suggestions for future research.

\section{Experimental Design}

Each experimental session consisted of 16 subjects that had to complete three stages. The number of participants was common knowledge. The first stage included a group assignment. More specifically, participants were asked to estimate the number of dots on a slide that was flashed on their computer screens. The division of participants into the two groups was thus based on a trivial criterion to eliminate variables that could potentially cause favoritism ex ante, such as racial background or gender. ${ }^{8}$ The subjects were assigned to two groups: Group A and Group B. To ensure an equal split, we placed those who provided an estimate above the median in Group A and those who provided an estimate at or below the median in Group B. The precise allocation rule was not disclosed. Instead, subjects were told that their group placement was based on the similarity of their estimate to those of the other participants. Subjects were, then, privately informed of their group label, which they retained for the entire duration of the experimental session. In the second stage, subjects had to participate in one of either the Trust game or the Dictator game. The games were played for 15 rounds. The number of rounds to come was not communicated to the participants. ${ }^{9}$ In each round, subjects' roles were determined by random draw. ${ }^{10}$ In addition, subjects had to face a different participant of the same or of different group identity in each round. ${ }^{11}$ In the third stage, subjects were asked to complete a questionnaire. With the conclusion of the experimental session, participants were privately paid their earnings in cash.

\footnotetext{
${ }^{8}$ Many experiments are designed to assess whether and to what extent people interact differently with in-group and out-group members. These experiments use either primed natural identities (Brown-Kruse and Hummels (1993), Cadsby and Maynes (1998), Bernhard, Fehr, and Fischbacher (2006), Goette, Huffman, and Meier (2006), Goette, Huffman, Meier, and Sutter (2012)) or induced identities (Charness, Rigotti, and Rustichini (2007), Hargreaves Heap and Zizzo (2009), Chen and Li (2009), Chen and Chen (2011)).

${ }^{9}$ In practice, however, the upper bound for the number of rounds to come could be determined. More specifically, as noted next, subjects were told that in each round they would face a different participant; thus, in a session with 16 subjects, the upper bound of rounds to come would be 15 .

${ }^{10}$ Alternatively, the subjects' roles could be kept fixed throughout the game. We thank an anonymous referee for suggesting this equally-interesting direction for research.

${ }^{11}$ The instructions were phrased as follows. "In the beginning of each round, you are matched with one other participant in the room. You will know whether the other participant is in-group (member of your own group) or out-group (member of the other group) but you will not know any other information pertaining to the other participant. In every round you will be matched with different participants of the same group membership or of different group membership. You will never be matched with the same participant twice." While the use of the terms "in-group" and "out-group" may have an impact on subjects' choices, any such effect should be constant within and across treatments.
} 


\section{$2.1 \quad$ Games}

In the standard Trust game (Berg, Dickhaut, and McCabe (1995)), one subject has the role of the first mover and the other subject has the role of the second mover. In the context of our setup, the first mover was initially given an endowment of 4 quarters and was asked to specify an integer amount of quarters, between zero and 4 quarters inclusive, to transfer to the second mover. On one hand, any quarters that were not transferred to the second mover were secured as profit for the first mover. On the other hand, the amount of transfer was multiplied by 4 before reaching the second mover. The second mover was asked next to allocate the new amount. The second mover, regardless of the first mover's transfer, had always a set of five options to choose from. Options differed in the allocation of the new amount between the second mover and the first mover. The options were explicitly mentioned in the experimental instructions as well as indicated on the subjects' computer screens. The round was completed with the earnings of the subject for the specific round indicated on the screen along with the cumulative earnings of the subject thus far in the game. The cumulative payoffs in the round of Group A and Group B were displayed on a screen right after the screen indicating the subject's earnings. Recall that a group's cumulative payoffs in the round consist of an aggregation of the earnings of each member of the group in the round. In the baseline, the groups' cumulative payoffs were not displayed.

In the standard Dictator game (Forsythe, Horowitz, Savin, and Sefton (1994)), the participant with the active role (the 'dictator') is provided with a monetary endowment. The dictator is, then, asked to allocate the endowment between himself and the passive participant with the understanding that the allocation will be implemented directly. In our setup, the dictator was given an endowment of quarters. Different numbers of quarters were provided as endowments, but the dictator would always face a set of five options to choose from. Options differed in the allocation of the endowment between the dictator and the passive participant. The options were explicitly mentioned in the experimental instructions as well as indicated on the subjects' computer screens. At the end of each round, the earnings of the subject for the specific round were indicated as well as the cumulative earnings so far in the game. Analogous to the Trust game, the groups' cumulative payoffs were displayed on the following screen, whereas in the baseline, the groups' cumulative payoffs were not displayed.

The experimental sessions were conducted in the XSFS computer lab of the Florida State University in May of 2010. The participants were recruited from the undergraduate population of the Florida State University using an electronic recruitment system, and were allowed to participate in only one session. Each session lasted approximately 45 minutes. Average earnings per participant were $\$ 8.31$. In addition, each participant was paid a $\$ 10$ show up 
fee. ${ }^{12}$ The experiments were programmed and conducted with the use of the experimental software z-Tree (Fischbacher (2007)). The experimental instructions are disclosed in the Appendix. Some general characteristics of the sessions are shown in Table 1.

Table 1: Characteristics of the Experimental Sessions

\begin{tabular}{lcccc}
\hline \hline Description & \# of rounds & \# of sessions & \# of subjects & Acronyms \\
\hline Treatments & 15 & 9 & 144 & GT \\
Trust game w/ group payoffs & 15 & 6 & 96 & GD \\
Dictator game w/ group payoffs & & & & \\
Baselines & 15 & 6 & 96 & NT \\
Trust game w/o group payoffs & 15 & 6 & 96 & ND \\
Dictator game w/o group payoffs & & & 432 & \\
\hline Total & & & & \\
\hline
\end{tabular}

Notes: In the first column, we provide a brief description of each treatment/baseline. In the second column, we show the corresponding number of rounds, which was fixed at 15 in all sessions. In the third column, we provide the number of sessions conducted. In each session we had 16 participants. In the fourth column, we provide the total number of participants in each treatment/baseline. The acronyms are reported in the last column. The following abbreviations are used: $\mathrm{G}=$ Group payoffs displayed; $\mathrm{N}=$ group payoffs Not displayed; $\mathrm{D}=$ Dictator game; $\mathrm{T}=$ Trust game.

\subsection{Payoffs and Options}

The first mover in the Trust game is asked to specify an integer amount of quarters that is transferred to the second mover. Let $i \in\{1,2\}$ index the order of the mover, and denote the amount of quarters transferred as $x \in\{0,1,2,3,4\}$. For a transfer $x$, the second mover receives $4 x$ quarters. If the first mover transfers 0 quarters, then, the game ends. Otherwise, the second mover has five options to choose from. Each option indicates the amount kept by the second mover (i.e. the payoff of the second mover) and the corresponding payoff of the first mover. The latter is provided in order to safeguard against calculation errors by subjects. The options are structured so as to provide variability in the allocation of $4 x$. The allocation structure is consistent across all transfers $x$. The first and fifth options are extreme in the sense that in the first option, the second mover keeps 0 quarters and the first mover

\footnotetext{
${ }^{12}$ The $\$ 10$ show up fee is a mandatory recruitment procedure required for all experiments conducted in the XSFS computer lab. Although the show up fee is relatively high, the participating subjects do respond to different treatments, so the show up fee is not overwhelming the marginal incentives from the experiment itself.
} 
gets $4 x$, whereas in the fifth option, the allocation is flipped so that the second mover gets $4 x$ and the first mover gets 0 quarters. The intermediate options are positioned across the two extremes. The second and fourth options distribute $4 x$ unevenly, with the first mover getting the bigger portion in the second option, and the second mover getting the bigger portion in the fourth option. Finally, the third option splits $4 x$ evenly across the first and second movers. Let $y \in\{1,2,3,4,5\}$ denote the choice of the second mover. Furthermore, let $\pi_{i}$ denote the payoff of mover $i$ in quarters. Given a transfer $x$ and choice $y$, the second mover's payoff is $\pi_{2}=(y-1) \times x$. The first mover's payoff is $\pi_{1}=4+3 x-\pi_{2}$; that is, the first mover earns $4-x$ in the first stage of the game and $4 x-\pi_{2}$ in the second stage of the game. For example, assume the first mover transfers 3 quarters to the second mover (i.e. $x=3$ ). The second mover receives $4 x=12$ quarters. Assume further that the second mover chooses the third option (i.e. $y=3)$. The second mover earns $\pi_{2}=(y-1) \times x=(3-1) \times 3=6$ quarters. The first mover gets the remaining 6 quarters, but this is not the final payoff of the first mover who, also, secured 1 quarter in the first stage of the game. Therefore, the first mover's profit is $\pi_{1}=3 x+4-\pi_{2}=3 \times 3+4-6=7$ quarters. Had the second mover chosen the second option (i.e. $y=2$ ), such a choice would correspond to a payoff of $\pi_{2}=(y-1) \times x=(2-1) \times 3=3$ quarters, whereas the first mover would earn a payoff of $\pi_{1}=3 x+4-\pi_{2}=3 \times 3+4-3=10$ quarters (see Panel B of Table 2).

In the Dictator game, let 1 index the passive subject and let 2 index the dictator. Recall that the dictator is given an endowment. In order to ensure that options are no different in pecuniary incentives across the two games, the endowment is $\tilde{x}=3 x+4$ for $x \in\{1,2,3,4\}$. Therefore, each transfer choice in the Trust game corresponds to a different endowment value. Given the transfer choices, the endowment values are $\tilde{x} \in\{7,10,13,16\}$. Let $y \in\{1,2,3,4,5\}$ be the choice of the dictator, and let $\pi_{i}$ denote the payoff of subject $i$ in quarters so that given any endowment $\tilde{x}$ and choice $y, \pi_{2}=(y-1)(\tilde{x}-4) / 3$ and $\pi_{1}=\tilde{x}-\pi_{2}$. Revisiting the previous example, recall that the first mover transfers 3 quarters to the second mover. Such a transfer corresponds to a dictator's endowment of $\tilde{x}=3 x+4=13$ quarters. A dictator faces the exact same five options as the second mover in the previous example. Assuming that the dictator also chooses the third option (i.e. $y=3$ ), the dictator's payoff is $\pi_{2}=(y-1)(\tilde{x}-4) / 3=(3-1)(13-4) / 3=6$ quarters. Given that the endowment is 13 quarters, the passive participant gets the remaining $\pi_{1}=\tilde{x}-\pi_{2}=13-6=7$ quarters. Alternatively, assuming that the dictator had chosen the second option (i.e. $y=2$ ), such a choice would correspond to a payoff of $\pi_{2}=(y-1)(\tilde{x}-4) / 3=(2-1)(13-4) / 3=3$ quarters, whereas the passive participant would earn a payoff of $\pi_{1}=\tilde{x}-\pi_{2}=13-3=10$ quarters. Notice that the payoffs are identical for the specific choices made across the two games. Table 2 generalizes the payoff comparability of options across the Trust game and 


\section{Table 2: Payoff Comparability of Options across Games}

\begin{tabular}{|c|c|c|c|}
\hline \multicolumn{4}{|l|}{ Panel $A$} \\
\hline Trust game & & Dictator game & \\
\hline First mover's payoff & $\pi_{1}=3 x+4-\pi_{2}$ & Dictator's payoff & $\pi_{1}=\tilde{x}-\pi_{2}$ \\
\hline Second mover's payoff & $\pi_{2}$ & Passive participant's payoff & $\pi_{2}$ \\
\hline \multirow[t]{8}{*}{ Panel $B$} & & \multirow{2}{*}{\multicolumn{2}{|c|}{ Transfer $x=1 /$ Endowment $\tilde{x}=7$}} \\
\hline & & & \\
\hline & Choice $y$ & $\pi_{1}$ & $\underline{\pi_{2}}$ \\
\hline & 1 & $\overline{7}$ & $\overline{0}$ \\
\hline & 2 & 6 & 1 \\
\hline & 3 & 5 & 2 \\
\hline & 4 & 4 & 3 \\
\hline & 5 & 3 & 4 \\
\hline
\end{tabular}

Transfer $x=2 /$ Endowment $\tilde{x}=10$

$\begin{array}{ccc}\text { Choice } y & \frac{\pi_{1}}{10} & \frac{\pi_{2}}{0} \\ 2 & 8 & 2 \\ 3 & 6 & 4 \\ 4 & 4 & 6 \\ 5 & 2 & 8\end{array}$

Transfer $x=3 /$ Endowment $\tilde{x}=13$

$\begin{array}{ccc}\text { Choice } y & \frac{\pi_{1}}{13} & \frac{\pi_{2}}{0} \\ 2 & 10 & 3 \\ 3 & 7 & 6 \\ 4 & 4 & 9 \\ 5 & 1 & 12\end{array}$

Transfer $x=4 /$ Endowment $\tilde{x}=16$

$\begin{array}{ccc}\text { Choice } y & \frac{\pi_{1}}{16} & \frac{\pi_{2}}{0} \\ 2 & 12 & 4 \\ 3 & 8 & 8 \\ 4 & 4 & 12 \\ 5 & 0 & 16\end{array}$

Notes: In the Trust game, the first mover's payoff is $\pi_{1}=4+3 x-\pi_{2}$. The second mover's payoff, given a transfer $x$ and choice $y$, is $\pi_{2}=(y-1) \times x$. In order to ensure payoff comparability of options across the two games, the endowment of the dictator is $\tilde{x}=3 x+4$ for a transfer $x \in\{1,2,3,4\}$. The dictator's endowment values are thus $\tilde{x} \in\{7,10,13,16\}$. If the first mover transfers 0 quarters, then, the game ends, and the first mover earns 4 quarters. 
the Dictator game. The particular payoff structure confirms that, not only the cardinality of the choice set is the same for all active participants across the two games, but, also, that the payoffs of the options across the games are the same. Hence, a change in behavior cannot be attributed to a change in the monetary incentives or the cardinality of the choice set.

\subsection{General Hypotheses}

We formulate next five hypotheses, which are divided into two groups. The first group formulates predictions on the role of the display of the comparative, but payoff irrelevant, information. The second group (with only one hypothesis) examines the role of the stage game, and investigates differences in the allocator's behavior across the Trust game and the Dictator game.

The first hypothesis aims to test whether the display of comparative, but payoff-irrelevant, information is sufficient to influence individual behavior in the group and induce an in-group bias. In light of the existing literature, ${ }^{13}$ we hypothesize that the display of group payoffs will invoke an in-group bias in both games. The first hypothesis is the following.

HYPOTHESIS 1: The display of comparative, but payoff-irrelevant, information invokes an in-group bias in both games.

To determine the effect of the display per se, we conducted additional experiments where no comparative information was displayed to establish a baseline (the experiments were otherwise identical). This enables us to test whether mere categorization of subjects into groups is sufficient to lead to behavioral differences across in-group and out-group members in accordance with the prediction of the Social Identity Theory. The early work of Tajfel and Turner (1986) motivates our second hypothesis.

HYPOTHESIS 2: Social Identity Theory postulates that mere categorization of subjects into groups is sufficient to induce an in-group bias in both games.

Our third hypothesis compares the group attachment scores of the participants when group payoffs are displayed with those when group payoffs are not displayed. As mentioned earlier, we have a measurement of group attachment, in the third stage of the experiment, based not on behavior, but on explicit statements of subjects (as in Yamagishi and Kiyonari (2000)). If the display of group payoffs had a substantial effect on group identity,

\footnotetext{
${ }^{13}$ We are aware of four studies that present a statistic on some variable(s) (Bohnet and Zeckhauser (2004), Frey and Meier (2004), Hargreaves Heap and Zizzo (2009), Chen, Harper, Konstan, and Li (2010)). With the exception of the study by Hargreaves Heap and Zizzo (2009), the other three studies are not group-based. All four studies, nevertheless, find that the display of the statistic (average or median) has a significant impact on participants' decisions.
} 
these measures of attachment should register a significant increase in the treatments where the group payoffs are displayed relative to the baselines. We thus hypothesize that any behavioral differences in the treatments (i.e. when group payoffs are displayed) may be due to a strengthening of the psychological ties amongst in-group members, which amplified participants' sense of group identity. Our third hypothesis is stated as follows.

HYPOTHESIS 3: The display of comparative, but payoff-irrelevant, information strengthens group attachment (as measured in the questionnaires) in both games.

The last hypothesis in the first group is based on the recent findings in the study of Hargreaves Heap and Zizzo (2009). Our fourth hypothesis tests whether the display of group payoffs in the Trust game is detrimental to the total welfare of first and second movers relative to the total welfare in the baseline. The fourth hypothesis is stated as follows.

HYPOTHESIS 4: In light of the recent findings in the study of Hargreaves Heap and Zizzo (2009), the display of comparative information will reduce the total welfare of first and second movers in the Trust game relative to that in the baseline.

Our single hypothesis in the second group is motivated by the cross-game comparisons when the allocator (the second mover in the Trust game and the dictator in the Dictator game) decides on the split. Many experimental studies find that allocation choices are sensitive to the behavior of the agent that generated the choice set (see, for instance, Berg, Dickhaut, and McCabe (1995)). We, thus, hypothesize that, controlling for the level of transfer/endowment and group identity, second movers return more to first movers compared to what dictators give to passive participants. The fifth hypothesis is formulated as follows. HYPOTHESIS 5: Based on existing literature (see, for instance, Berg, Dickhaut, and McCabe (1995)), second movers will return more to first movers compared to what dictators give to passive participants when controlling for the level of transfer/endowment and identity.

\section{Results}

We first report some descriptive statistics of the experimental sessions. We, then, test the five general hypotheses. In Subsection 3.2, we report our findings on the first three hypotheses, which pertain to the behavior of second movers and dictators, and in Subsection 3.3, we clarify the role of public signals. In Subsection 3.4, we report welfare results with respect

to the first movers' behavior in the Trust game. In Subsection 3.5, we provide cross-game comparisons on behavioral differences when the allocator decides on the split. 


\subsection{Descriptive Statistics}

Table 3 reports descriptive statistics on the raw experimental data. In particular, the frequency of the transfer in the Trust game and the choice variables in, both, the Dictator and the Trust game are presented. Notice that in the Dictator game, $82.1 \%$ of the subjects acting as dictators chose to keep the maximum allowable amount. The percentage of dictators who chose to keep the maximum allowable amount was $87.5 \%$ when they were matched with out-group members and $75.9 \%$ when matched with in-group members. In addition, it is, also, worth noticing that only choices $y=3,4,5$ have a strictly positive number of observations in the Dictator game. Similarly, we observe differences across group identities in the Trust game. More specifically, only $27.2 \%$ of the first movers transferred more than half of their endowment to out-group members. The percentage of first movers who transferred more than half of their endowment to in-group members was $41.4 \%$. Furthermore, $60.7 \%$ of second movers kept the entire allowable amount when matched with an out-group member versus $53.5 \%$ when matched with an in-group member. ${ }^{14}$

Table 4 reports first mover's behavior in the Trust game. The percentage of transfers to out-group members that are 3 or 4 quarters decreases substantially with the display of group payoffs. More specifically, without the display of group payoffs $38.3 \%$ transfer either 3 or 4 quarters, whereas with the display of group payoffs less than $20 \%$ of first movers transfer 3 or 4 quarters to out-group second movers. Consequently, the percentage of first movers that transfer 0,1 or 2 quarters to out-group second movers increases with the display of group payoffs from $61.6 \%$ to a little bit over $80 \%$. For in-group members, the changes in percentages without the display of group payoffs versus with the display of group payoffs are moderate. In particular, $40.2 \%$ of in-group members transfer 3 or 4 quarters without the display of group payoffs and $42.1 \%$ transfer 3 or 4 quarters with the display of group payoffs. On the other end, $59.8 \%$ transfer 0,1 or 2 quarters to in-group second movers without the display of group payoffs and $57.9 \%$ transfer 0,1 or 2 quarters to in-group second movers with the display of group payoffs.

Table 5 shows the distribution of each choice $y$. In particular, we show how the distribution of each choice $y$ changes with the endowment $\tilde{x}$ in the Dictator game, and how it changes with the first mover's transfer $x$ in the Trust game. In the Dictator game, when the endowment was 7 quarters, $93.2 \%$ of the dictators chose to keep the entire amount in, both, the baseline and the treatment. This percentage dropped when the endowment was 16 quarters. More specifically, the proportion of dictators who chose to keep the entire amount was $77.7 \%$ in the baseline, and $68.1 \%$ when group payoffs were displayed. However, in the

\footnotetext{
${ }^{14}$ The choice of 12 second movers to 'return' the entire amount to first movers $(y=1)$ is most likely an error on the part of second movers. Our results hold even after removing those 12 observations.
} 
Table 3: Transfers and Choices Across Games and Identities

\begin{tabular}{|c|c|c|c|c|c|c|}
\hline Dictator game & \multicolumn{2}{|c|}{ Overall } & \multicolumn{2}{|c|}{ Out-group } & \multicolumn{2}{|c|}{ In-group } \\
\hline Choice $y$ & Freq. & Percent & Freq. & Percent & Freq. & Percent \\
\hline 1 & 0 & 0.0 & 0 & 0.0 & 0 & 0.0 \\
\hline 2 & 0 & 0.0 & 0 & 0.0 & 0 & 0.0 \\
\hline 3 & 51 & 3.5 & 18 & 2.3 & 33 & 4.9 \\
\hline 4 & 207 & 14.4 & 78 & 10.2 & 129 & 19.2 \\
\hline 5 & 1182 & 82.1 & 672 & 87.5 & 510 & 75.9 \\
\hline Total & 1440 & & 768 & & 672 & \\
\hline Trust game & \multicolumn{2}{|c|}{ Overall } & \multicolumn{2}{|c|}{ Out-group } & \multicolumn{2}{|c|}{ In-group } \\
\hline Transfer $x$ & Freq. & Percent & Freq. & Percent & Freq. & Percent \\
\hline 0 & 633 & 35.2 & 387 & 40.3 & 246 & 29.3 \\
\hline 1 & 204 & 11.3 & 126 & 13.1 & 78 & 9.3 \\
\hline 2 & 354 & 19.7 & 186 & 19.4 & 168 & 20.0 \\
\hline 3 & 129 & 7.2 & 60 & 6.3 & 69 & 8.2 \\
\hline 4 & 480 & 26.7 & 201 & 20.9 & 279 & 33.2 \\
\hline Total & 1800 & & 960 & & 840 & \\
\hline Trust game & \multicolumn{2}{|c|}{ Overall } & \multicolumn{2}{|c|}{ Out-group } & \multicolumn{2}{|c|}{ In-group } \\
\hline Choice $y$ & Freq. & Percent & Freq. & Percent & Freq. & Percent \\
\hline 1 & 12 & 1.0 & 6 & 1.1 & 6 & 1.0 \\
\hline 2 & 0 & 0.0 & 0 & 0.0 & 0 & 0.0 \\
\hline 3 & 171 & 14.7 & 54 & 9.4 & 117 & 19.7 \\
\hline 4 & 318 & 27.3 & 165 & 28.8 & 153 & 25.8 \\
\hline 5 & 666 & 57.1 & 348 & 60.7 & 318 & 53.5 \\
\hline Total & 1167 & & 573 & & 594 & \\
\hline
\end{tabular}

Notes: If the first mover in the Trust game transfers 0 quarters, then, the game ends; thus, the frequency of choice $y$ is conditional on a transfer $x>0$.

Trust game, the percentage change is more radical and dependent on the magnitude of the transfer. For example, when first movers transferred only one quarter, then, $92.6 \%$ of the second movers in the baseline, and $87.8 \%$ of the second movers when group payoffs were displayed, chose to keep the entire amount. Yet when second movers received a transfer of two quarters, the percentage of them who kept the entire amount dropped to $46.9 \%$ and $52.2 \%$, respectively. The percentages remained relatively low when the transfer was 3 quarters and 4 quarters. 
Table 4: First Movers' Behavior in the Trust Game

\begin{tabular}{crrrr}
\hline \hline Out-group & \multicolumn{2}{c}{ NT } & \multicolumn{2}{c}{ GT } \\
\hline Transfer & Freq. & Percent & Freq. & Percent \\
\hline 0 & 105 & 27.3 & 282 & 49.0 \\
1 & 42 & 10.9 & 84 & 14.6 \\
2 & 90 & 23.4 & 96 & 16.7 \\
3 & 54 & 14.1 & 6 & 1.0 \\
4 & 93 & 24.2 & 108 & 18.8 \\
\hline Total & 384 & & 576 & \\
\hline \hline In-group & & NT & & GT \\
\hline Transfer & Freq. & Percent & Freq. & Percent \\
\hline 0 & 81 & 27.3 & 165 & 30.3 \\
1 & 39 & 13.2 & 39 & 7.2 \\
2 & 57 & 19.3 & 111 & 20.4 \\
3 & 24 & 8.1 & 45 & 8.3 \\
4 & 95 & 32.1 & 184 & 33.8 \\
\hline Total & 296 & & 544 &
\end{tabular}

Notes: The table reports the behavior of first movers in the Trust game for all possible transfer amounts. The Trust game without the display of group payoffs is a baseline. The following abbreviations are used: $\mathrm{G}$ $=$ Group payoffs displayed; $\mathrm{N}=$ group payoffs Not displayed; $\mathrm{D}=$ Dictator game; $\mathrm{T}=$ Trust game.

\subsection{Second Movers' and Dictators' Behavior}

We analyze, next, the allocators' behavior using a standard ordinal probit regression. ${ }^{15}$ Recall that the allocator is the second mover in the Trust game or the dictator in the Dictator game. To clearly assess the effect of the display of group payoffs on agents' decisions, we categorize all the observations based on the following criteria:

\footnotetext{
${ }^{15}$ As explained in Subsection 2.2, $y_{i} \in\{1,2,3,4,5\}$ denotes the choice of the allocator $i$, where each choice corresponds to a different payoff distribution. Given that the allocator's choice is not a continuous variable, the most suitable test to conduct data analysis is the ordinal probit regression.
} 
Table 5: Distribution of Choice

\begin{tabular}{|c|c|c|c|c|c|c|c|c|}
\hline \multirow{3}{*}{$\begin{array}{ll} & \text { Endowment } \tilde{x} \\
\text { Choice } y & \end{array}$} & \multicolumn{8}{|c|}{ ND } \\
\hline & \multicolumn{2}{|r|}{7} & \multicolumn{2}{|c|}{10} & \multicolumn{2}{|c|}{13} & \multicolumn{2}{|c|}{16} \\
\hline & Freq. & Percent & Freq. & Percent & Freq. & Percent & Freq. & Percent \\
\hline 1 & 0 & 0.0 & 0 & 0.0 & 0 & 0.0 & 0 & 0.0 \\
\hline 2 & 0 & 0.0 & 0 & 0.0 & 0 & 0.0 & 0 & 0.0 \\
\hline 3 & 3 & 2.3 & 0 & 0.0 & 0 & 0.0 & 18 & 6.4 \\
\hline 4 & 6 & 4.5 & 30 & 13.0 & 9 & 12.0 & 45 & 16.0 \\
\hline 5 & 123 & 93.2 & 201 & 87.0 & 66 & 88.0 & 219 & 77.7 \\
\hline
\end{tabular}

GD

\begin{tabular}{cccccccccc}
\hline \multirow{2}{*}{ Choice $y$} & Endowment $\tilde{x}$ & \multicolumn{2}{c}{7} & \multicolumn{2}{c}{10} & \multicolumn{2}{c}{13} \\
\cline { 2 - 8 } & & Freq. & Percent & Freq. & Percent & Freq. & Percent & Freq. & Percent \\
\hline 1 & 0 & 0.0 & 0 & 0.0 & 0 & 0.0 & 0 & 0.0 \\
2 & 0 & 0.0 & 0 & 0.0 & 0 & 0.0 & 0 & 0.0 \\
3 & 0 & 0.0 & 3 & 1.3 & 0 & 0.0 & 27 & 9.6 \\
4 & 9 & 6.8 & 36 & 15.6 & 9 & 12.0 & 63 & 22.3 \\
5 & 123 & 93.2 & 192 & 83.1 & 66 & 88.0 & 192 & 68.1 \\
\hline \hline
\end{tabular}

\begin{tabular}{|c|c|c|c|c|c|c|c|c|}
\hline \multirow{3}{*}{$\begin{array}{ll}\text { Choice } y & \text { Transfer } x \\
\end{array}$} & \multicolumn{8}{|c|}{$\mathrm{NT}$} \\
\hline & \multicolumn{2}{|c|}{1} & \multicolumn{2}{|c|}{2} & \multicolumn{2}{|c|}{3} & \multicolumn{2}{|r|}{4} \\
\hline & Freq. & Percent & Freq. & Percent & Freq. & Percent & Freq. & Percent \\
\hline 1 & 3 & 3.7 & 3 & 2.0 & 0 & 0.0 & 0 & 0.0 \\
\hline 2 & 0 & 0.0 & 0 & 0.0 & 0 & 0.0 & 0 & 0.0 \\
\hline 3 & 0 & 0.0 & 0 & 0.0 & 6 & 7.7 & 75 & 39.9 \\
\hline 4 & 3 & 3.7 & 75 & 51.0 & 42 & 53.9 & 60 & 31.9 \\
\hline 5 & 75 & 92.6 & 69 & 46.9 & 30 & 38.5 & 53 & 28.2 \\
\hline
\end{tabular}

\begin{tabular}{|c|c|c|c|c|c|c|c|c|}
\hline \multirow{3}{*}{$\begin{array}{ll}\text { Choice } y & \text { Transfer } x \\
\end{array}$} & \multicolumn{8}{|c|}{ GT } \\
\hline & \multicolumn{2}{|r|}{1} & \multicolumn{2}{|c|}{2} & \multicolumn{2}{|c|}{3} & \multicolumn{2}{|r|}{4} \\
\hline & Freq. & Percent & Freq. & Percent & Freq. & Percent & Freq. & Percent \\
\hline 1 & 3 & 2.4 & 0 & 0.0 & 3 & 5.9 & 0 & 0.0 \\
\hline 2 & 0 & 0.0 & 0 & 0.0 & 0 & 0.0 & 0 & 0.0 \\
\hline 3 & 0 & 0.0 & 15 & 7.2 & 3 & 5.9 & 72 & 24.7 \\
\hline 4 & 12 & 9.8 & 84 & 40.6 & 15 & 29.4 & 27 & 9.2 \\
\hline 5 & 108 & 87.8 & 108 & 52.2 & 30 & 58.8 & 193 & 66.1 \\
\hline
\end{tabular}

Notes: Each transfer amount corresponds to an endowment value. A transfer $x \in\{1,2,3,4\}$ is mapped onto an endowment value $\tilde{x}=3 x+4$. The set of endowment values is thus $\{7,10,13,16\}$. The Dictator game without the display of group payoffs and the Trust game without the display of group payoffs are baselines. The following abbreviations are used: $\mathrm{G}=$ Group payoffs displayed; $\mathrm{N}=$ group payoffs Not displayed; $\mathrm{D}=$ Dictator game; $\mathrm{T}=$ Trust game. 


$$
\begin{aligned}
& G=\text { Group payoffs displayed, } \\
& D=\text { Dictator game played, } \\
& I=\text { In-group match, } \\
& N=\text { group payoffs Not displayed, } \\
& T=\text { Trust game played, } \\
& O=\text { Out-group match. }
\end{aligned}
$$

Based on these criteria, there are 8 different alternatives: NDO, NDI, GDO, GDI, NTO, NTI, GTO and GTI. These alternatives are mutually exclusive, so we create a dummy variable associated with each of the eight alternatives. For example, dummy variable $1_{N D O, i}=1$ when allocator $i$ is playing in the Dictator game with an out-group participant and group payoffs are not displayed, and $1_{N D O, i}=0$ when allocator $i$ is playing in any of the other seven alternatives. Crucially, we control for the level of transfer/endowment an allocator receives using the following dummy variables:

$$
\begin{aligned}
& 1_{x, \forall x \in\{1,2,3,4\}}= \begin{cases}1 & \text { if transfer in Trust game is } \mathrm{x} \\
0 & \text { if transfer in Trust game is not } \mathrm{x}\end{cases} \\
& 1_{\tilde{x}, \forall \tilde{x} \in\{7,10,13,16\}}= \begin{cases}1 & \text { if endowment in Dictator game is } \tilde{x} \\
0 & \text { if endowment in Dictator game is not } \tilde{x} .\end{cases}
\end{aligned}
$$

Let $y_{i}^{*}$ be the unobserved dependent variable. The regression model is specified as

$$
y_{i}^{*}=\sum_{u \in\{G, N\}} \sum_{v \in\{D, T\}} \sum_{w \in\{O, I\}} \beta_{u v w} \cdot 1_{u v w, i}+\sum_{x \in\{1,2,3,4\}} \alpha_{D x} \cdot 1_{x, i}+\sum_{\tilde{x} \in\{7,10,13,16\}} \alpha_{T \tilde{x}} \cdot 1_{\tilde{x}, i}+\varepsilon_{i} .
$$

The relationship between the latent variable $y_{i}^{*}$ and observable $y_{i}$ is

$$
y_{i}= \begin{cases}1 & \text { if } y_{i}^{*} \leq \mu_{1} \\ 2 & \text { if } \mu_{1}<y_{i}^{*} \leq \mu_{2} \\ 3 & \text { if } \mu_{2}<y_{i}^{*} \leq \mu_{3} \\ 4 & \text { if } \mu_{3}<y_{i}^{*} \leq \mu_{4} \\ 5 & \text { if } \mu_{4}<y_{i}^{*}\end{cases}
$$

In Table 6, we report the estimated values of the coefficients from the regression model. Recall that an allocator's choice is associated with a different payoff for the allocator. Therefore, relative to the base, a positive estimated value corresponds to an allocator who is more likely to keep more and, thus, give less to the first mover/passive participant; however, a 
Table 6: Estimated Values

\begin{tabular}{|c|c|c|c|}
\hline Treatment & $\beta$ Coefficients & Endowment & $\begin{array}{l}\alpha \text { Coefficients } \\
\text { Dictator game }\end{array}$ \\
\hline $\mathrm{NDO}$ & Base & 7 & $\begin{array}{l}0.820^{* * *} \\
(0.140)\end{array}$ \\
\hline NTO & $\begin{array}{c}-0.910^{\text {*** }} \\
(0.139)\end{array}$ & 10 & $\begin{array}{l}0.473^{\text {*** }} \\
(0.090)\end{array}$ \\
\hline GDO & $\begin{array}{c}0.185^{*} \\
(0.112)\end{array}$ & 13 & $\begin{array}{l}0.654^{* * *} \\
(0.134)\end{array}$ \\
\hline GTO & $\begin{array}{c}-0.526^{* * *} \\
(0.150)\end{array}$ & 16 & Base \\
\hline NDI & -0.011 & Transfer & Trust game \\
\hline NTI & $\begin{array}{c}(0.124) \\
-0.925^{* * *}\end{array}$ & 1 & $\begin{array}{l}1.176^{* * *} \\
(0.151)\end{array}$ \\
\hline GDI & $\begin{array}{c}(0.128) \\
-0.483^{* * *}\end{array}$ & 2 & $\begin{array}{c}0.256^{* * *} \\
(0.088)\end{array}$ \\
\hline \multirow[t]{2}{*}{ GTI } & $\begin{array}{c}(0.098) \\
-0.863^{* * *}\end{array}$ & 3 & $\begin{array}{c}0.208^{*} \\
(0.115)\end{array}$ \\
\hline & $(0.145)$ & 4 & Dropped \\
\hline
\end{tabular}

Notes: We conduct ordinal probit regression and report, in the table, the estimated values of the coefficients. Alternative $N D O$ with an endowment of 16 quarters is the base in the regression. The $\mu$ coefficients summarize the regression results under the base. For example, if $y_{i}^{*}$ is less than or equal to the estimated $\mu_{1}$, then, the model predicts that an allocator $i$ would choose $y_{i}=1$ in alternative $N D O$ with an endowment of 16 quarters. From the estimation, the cutoffs are: $\mu_{1}=-2.997, \mu_{3}=-1.629$, and $\mu_{4}=-0.700$. Choice $y_{i}=2$ has no observations in the data; thus, $\mu_{2}$ is dropped in the regression. The $\beta$ and $\alpha$ coefficients report differences from the base. For example, the model predicts that an allocator $i$ would choose $y_{i}=1$ in alternative $N T O$ with a transfer of 1 quarter if $y_{i}^{*} \leq \mu_{1}+\beta_{N T O}+\alpha_{x=1}$. The Trust game coefficient $\alpha_{x=4}$ is dropped due to collinearity. The following abbreviations are used: $\mathrm{G}=$ Group payoffs displayed; $\mathrm{N}=$ group payoffs Not displayed; $\mathrm{I}=$ In-group; $\mathrm{O}=$ Out-group; $\mathrm{T}=$ Trust game; $\mathrm{D}=$ Dictator game. Standard errors, reported in parentheses, are clustered at the individual level. *** Significant at the $1 \%$ level. ** Significant at the $5 \%$ level. ${ }^{*}$ Significant at the $10 \%$ level.

negative estimated value corresponds to an allocator who is more likely to keep less and, thus, give more to the first mover/passive participant. Based on the ordinal probit regression results, reported in Table 6, we construct Table 7, which interprets second movers' and dictators' behavior. The latter table will enable us to test the first two general hypotheses. Our first hypothesis aims to test whether the display of comparative, but payoff-irrelevant, information is sufficient to influence individual behavior in the group and promote an ingroup bias. Recall that, controlling for the game and the display, an allocator's payoff when matched with an out-group member that is significantly larger than the allocator's payoff 
when matched with an in-group member is interpreted as evidence of an in-group bias. The findings are formalized in our first result.

RESULT 1: The display of comparative, but payoff-irrelevant, information invokes an ingroup bias in both games.

Support. In Panel A of Table 7, GD ( $p$-value $=0.000)$ and GT $(p$-value $=0.002)$ establish that the display is sufficient to induce an in-group bias.

\section{Table 7: Second Movers' And Dictators' Behavior}

\begin{tabular}{lcc}
\hline \hline \multirow{2}{*}{$\begin{array}{l}\text { Panel } A \\
\text { Null hypothesis: }\end{array}$} & & \\
& & in-group $\geq$ out-group \\
\cline { 2 - 3 } ND & Estimated values & $p$-values \\
NT & -0.011 & 0.465 \\
GD & -0.015 & 0.443 \\
GT & -0.668 & 0.000 \\
& -0.337 & 0.002 \\
\hline \hline
\end{tabular}

Panel B.1

Out-group

Null hypothesis:

$$
\mathrm{w} / \text { display } \leq \mathrm{w} / \mathrm{o} \text { display }
$$

Estimated values

$p$-values

Dictator game

0.185

0.050

Trust game

0.385

0.002

\section{Panel B.2}

In-group

Null hypothesis:

$$
\mathrm{w} / \text { display } \geq \mathrm{w} / \mathrm{o} \text { display }
$$

Estimated values

$$
p \text {-values }
$$

Dictator game

$-0.472$

0.000

Trust game

0.062

0.702

Notes: The table interprets second movers' and dictators' behavior based on the ordinal probit regression results reported in Table 6. Panel A tests for an in-group bias. Panel B1 and B2 investigate behavioral changes as a result of the display of group payoffs when allocators are matched with out-group and in-group participants. For hypothesis testing, one tailed z-tests are used in all panels. The following abbreviations are used: $\mathrm{G}=$ Group payoffs displayed; $\mathrm{N}=$ group payoffs Not displayed; $\mathrm{D}=$ Dictator game; $\mathrm{T}=$ Trust game. 
However, it is plausible that the observed behavioral differences are not due to the effect of the display, but due to mere categorization of subjects into groups; the latter might have culminated in a strong sense of group identity that led to the in-group bias. Our second result summarizes our findings.

RESULT 2: Mere categorization of subjects into groups is not sufficient to induce an in-group bias in either game in sharp contrast to the prediction of the Social Identity Theory.

Support. In Panel A of Table 7, ND $(p$-value $=0.465)$ and NT $(p$-value $=0.443)$ highlight that mere categorization of subjects into groups is not sufficient to invoke an in-group bias.

Our second result indicates that group assignment alone is not sufficient to invoke an in-group bias, whereas our first result demonstrates that the display is sufficient to invoke an in-group bias. Next, we investigate further to determine how does the display alter the allocators' behaviors precisely. In Panel B.1, our Null states that an allocator's payoff when matched with an out-group participant and group payoffs are not displayed is greater or equal to that when group payoffs are displayed. In Panel B.2, our Null states that an allocator's payoff when matched with an in-group participant is greater or equal when group payoffs are displayed to that when group payoffs are not displayed. On one hand, in the out-group panel, the Null is rejected in both games; that is, both second movers and dictators give significantly less to out-group participants when group payoffs are displayed than when they are not. On the other hand, in the in-group panel, dictators give significantly more to ingroup participants when group payoffs are displayed than when they are not, but this is not the case with second movers in the Trust game.

In light of the recent literature on group manipulations (see Charness, Rigotti, and Rustichini (2007) and Chen and $\mathrm{Li}$ (2009)), a plausible interpretation of our results is that the display of group payoffs has amplified group identity. To determine whether the display of group payoffs, indeed, enhanced the psychological ties amongst in-group members, we conducted additional analysis on the participants' group attachment as measured in the post-experimental questionnaire. Similar to Yamagishi and Kiyonari (2000), there were eight questions that dealt with the degree of close attachment, commonality, belongingness and liking towards members of their own group and towards members of the other group. The participants' degree of attachment was measured on a scale from 1 to 10. Crucially, if the display of group payoffs did invoke substantial enhancement of group identity, this effect should appear in the self-reported attachment of participants.

In Table 8, we construct and report the mean difference between in-group attachment and out-group attachment for each individual subject. In particular, Panel A reports the mean difference in attachment for subjects who participated either in the Dictator game or the 
Trust game with or without the display of group payoffs. Even though the mean difference in attachment is higher in the treatments with the display of group payoffs in both games, the mean difference is not statistically significant in either game as shown in Panel B. The findings are summarized in our third result. ${ }^{16}$

Table 8: Mean Difference Between In-group and Out-Group Attachment

\begin{tabular}{lc}
\hline \hline \multirow{2}{*}{ Panel $A$} & Mean difference in attachment \\
\cline { 2 - 2 } ND & In-group attachment - Out-group attachment \\
& 0.875 \\
GD & $(0.446)$ \\
& 1.250 \\
NT & $(0.537)$ \\
& 0.969 \\
GT & $(0.429)$ \\
& 1.563 \\
\hline \hline \multirow{2}{*}{ Panel B } & $(0.442)$ \\
Null hypothesis: & \\
\cline { 2 - 2 } Dictator game & w/ group payoffs $\leq \mathrm{w} /$ o group payoffs \\
Trust game & 0.583 \\
\hline
\end{tabular}

Notes: Panel A reports the mean difference in attachment for participants who participated in the Dictator game and in the Trust game. In Panel A, standard errors are reported in parentheses. In Panel B, we use the Mann-Whitney test to determine whether the mean difference across the two games is statistically different. The Dictator game without the display of group payoffs and the Trust game without the display of group payoffs are baselines. The following abbreviations are used: $\mathrm{G}=$ Group payoffs displayed; $\mathrm{N}=$ group payoffs Not displayed; $\mathrm{D}=$ Dictator game; $\mathrm{T}=$ Trust game.

RESULT 3: The display of comparative, but payoff-irrelevant, information does not induce significant additional group attachment.

Support. We do not find evidence of a significant difference in the mean difference in attachment in the Dictator game $(p$-value $=0.583)$ or the Trust game $(p$-value $=0.594)$.

\footnotetext{
${ }^{16}$ Using the two-sided Mann-Whitney, we, also, tested whether the group attachment without the display of group payoffs is less than the group attachment with the display of group payoffs for in-group participants in the Dictator game $(p$-value $=0.546)$, out-group participants in the Dictator game $(p$-value $=0.530)$, in-group participants in the Trust game $(p$-value $=0.567)$ and out-group participants in the Trust game $(p$-value $=0.496)$. Our findings corroborate our third result.
} 


\subsection{The Role of Public Signals}

Based on the first three results, we have narrowed down the possible explanations of why the display induces an in-group bias. The remaining yet untested hypothesis is sketched next. It is important though, first, to highlight that the shaping of group identity is a process that should not be considered complete as soon as subjects are assigned to groups. The building of group identity is unlikely to be the almost-automatic response, triggered by minimal signs, as it seems in Tajfel's tradition. There must be a build-up; that is, a learning process based on accumulation and reinforcement of experiences. This is evident in Table 9, which presents a breakdown, into blocks of 5 rounds each (i.e. 1-5, 6-10, 11-15), of the second movers' and dictators' behavior of Panel A in Table 7. Clearly, in GD and in GT, the absolute values of the estimated coefficients are getting bigger as subjects' experience accumulates, and so does the significance of the in-group bias effect.

A corollary of the Social Identity Theory is that participants in Tajfel's minimal group experiments would treat in-group members more favorably as a way of making their own group positively distinct. Clearly, however, the esteem of one's group is hardly improved if the better outcome is not due to the special skills of the members of the group, but, instead, to favoritism of in-group members at the moment of deciding an allocation. This suggests that knowledge of outcomes serves more as a coordination device rather than as an indication on the skills of the group members. We, thus, conjecture that the display of group payoffs acts as a public signal that makes groups salient; in turn, such group-based information saliency induces an in-group bias. In our view, a stronger group identity is the outcome, rather than the cause, of the in-group bias. We emphasize that we are not excluding the possibility that the display of group payoffs in longer experimental sessions might, eventually, significantly affect group attachment. Such findings, however, would suggest that, indeed, the display works as a public signal facilitating an in-group bias, which culminates in an enhanced group identity.

\subsection{Welfare in the Trust Game}

In the previous subsection, we discussed and formalized results with respect to second movers' and dictators' behavior. In this subsection, we focus on first movers' behavior. Our motivation is to determine if the display reduces the total welfare relative to the baseline. In Table 10, we report the mean first movers' transfers in the Trust game in four alternatives: NTO, GTO, NTI and GTI. Our fourth result is summarized next. 
Table 9: Evolution of In-Group Bias

\begin{tabular}{|c|c|c|}
\hline \multicolumn{3}{|l|}{ Rounds 1-5 } \\
\hline \multirow[t]{2}{*}{ Null hypothesis: } & & in-group $\geq$ out-group \\
\hline & Estimated values & $p$-values \\
\hline ND & 0.027 & 0.562 \\
\hline NT & -0.106 & 0.222 \\
\hline GD & -0.277 & 0.046 \\
\hline GT & -0.205 & 0.048 \\
\hline \multicolumn{3}{|l|}{ Rounds 6-10 } \\
\hline \multirow[t]{2}{*}{ Null hypothesis: } & & in-group $\geq$ out-group \\
\hline & Estimated values & $p$-values \\
\hline ND & -0.081 & 0.381 \\
\hline NT & -0.287 & 0.168 \\
\hline GD & -0.629 & 0.000 \\
\hline GT & -0.441 & 0.007 \\
\hline \multicolumn{3}{|l|}{ Rounds 11-15 } \\
\hline \multirow[t]{2}{*}{ Null hypothesis: } & & in-group $\geq$ out-group \\
\hline & Estimated values & $p$-values \\
\hline ND & -0.026 & 0.446 \\
\hline NT & 0.107 & 0.741 \\
\hline GD & -1.230 & 0.000 \\
\hline GT & -0.506 & 0.000 \\
\hline
\end{tabular}

Notes: This table presents a breakdown, into blocks of 5 rounds each, of the second movers' and dictators' behavior of Panel A in Table 7. Similar to Table 7, an ordinal probit regression is used to analyze data from each block. For hypothesis testing, one tailed z-tests are used. The following abbreviations are used: $\mathrm{G}=$ Group payoffs displayed; $\mathrm{N}=$ group payoffs Not displayed; $\mathrm{D}=$ Dictator game; $\mathrm{T}=$ Trust game.

RESULT 4: In line with the recent findings in the study of Hargreaves Heap and Zizzo (2009), the display of comparative information reduces the total welfare in the Trust game relative to the baseline.

Support. Panel A of Table 10 shows that, when matched with out-group second movers, the mean first mover's transfer is significantly less when group payoffs are displayed ( $p$-value $=0.007)$. Panel $\mathrm{B}$ of Table 10 shows that, when matched with in-group second movers, the mean first mover's transfer is not significantly more when group payoffs are displayed $(p$-value $=0.922)$. These findings, together, establish that the display of group payoffs is welfare reducing. 


\section{Table 10: First Movers' Behavior}

\begin{tabular}{|c|c|c|}
\hline Panel $A$ & & \\
\hline Out-group & Mean & \\
\hline NT & $\begin{array}{c}2.710 \\
(0.065)\end{array}$ & \\
\hline GT & $\begin{array}{c}2.469 \\
(0.073)\end{array}$ & \\
\hline Null hypothesis: & & $\mathrm{w} /$ display $\geq \mathrm{w} / \mathrm{o}$ display \\
\hline GTO - NTO & $\begin{array}{l}-0.240 \\
(0.098)\end{array}$ & $\begin{array}{c}p \text {-values } \\
0.007\end{array}$ \\
\hline Panel B & & \\
\hline In-group & Mean & \\
\hline NT & $\begin{array}{c}3.000 \\
(0.073)\end{array}$ & \\
\hline GT & $\begin{array}{c}2.867 \\
(0.059)\end{array}$ & \\
\hline Null hypothesis: & & $\mathrm{w} /$ display $\leq \mathrm{w} / \mathrm{o}$ display \\
\hline GTI - NTI & $\begin{array}{l}-0.133 \\
(0.093)\end{array}$ & $\begin{array}{c}p \text {-values } \\
0.922\end{array}$ \\
\hline
\end{tabular}

Notes: Panel A reports the means of first movers' transfers when matched with out-group participants, and tests whether the mean transfer is less when group payoffs are displayed versus when they are not. Panel B reports corresponding results on in-group matches. One-tailed t-tests are used in both panels. The following abbreviations are used: $\mathrm{G}=$ Group payoffs displayed; $\mathrm{N}=$ group payoffs Not displayed; $\mathrm{I}=$ In-group; $\mathrm{O}=$ Out-group; $\mathrm{T}=$ Trust game; $\mathrm{D}=$ Dictator game.

\subsection{Cross-Game Comparability}

Our experimental design, also, incorporates carefully-chosen payments in the Trust game and the Dictator game to ensure that payoffs in the two games are comparable. Our construction is, thus, well suited for cross-game comparisons to determine any behavioral differences when the allocator decides on the split. Panel A of Table 11 reports whether first mover's trust is reciprocated by the second movers when controlling for the level of transfer/endowment and group identity. Our findings are formalized in our final result. 
Table 11: Reciprocation of Trust

\begin{tabular}{|c|c|c|}
\hline \multicolumn{3}{|l|}{ Panel $A$} \\
\hline \multirow[t]{2}{*}{ Null hypothesis: } & \multirow[b]{2}{*}{ Estimated values } & Trust game $\geq$ Dictator game \\
\hline & & $p$-values \\
\hline \multicolumn{3}{|l|}{ Out-group } \\
\hline $\mathrm{W} / \mathrm{o}$ display & -0.910 & 0.000 \\
\hline $\mathrm{W} /$ display & -0.711 & 0.000 \\
\hline \multicolumn{3}{|l|}{ In-group } \\
\hline $\mathrm{W} / \mathrm{o}$ display & -0.914 & 0.000 \\
\hline $\mathrm{W} /$ display & -0.380 & 0.003 \\
\hline \multicolumn{3}{|l|}{ Panel B } \\
\hline \multirow[t]{2}{*}{ Null hypothesis: } & & in-group diff. = out-group diff. \\
\hline & Estimated values & $p$-values \\
\hline $\begin{array}{l}\text { W/o display } \\
(\mathrm{NTI}-\mathrm{NDI})-(\mathrm{NTO}-\mathrm{NDO})\end{array}$ & -0.004 & 0.982 \\
\hline $\begin{array}{l}\text { W/ display } \\
(\text { GTI - GDI }) \text { - (GTO - GDO })\end{array}$ & 0.331 & 0.028 \\
\hline
\end{tabular}

Notes: The table reports tests to investigate, first, whether first mover's trust is reciprocated by the second movers when controlling for the level of transfer/endowment and group identity, and, second, the degree of reciprocation across groups. All estimated values are based on the ordinal probit regression results of Table 6. Panel A tests whether a second mover's payoff is less than that of the dictator. Panel B conducts a difference in different test to determine whether the in-group difference is different from the out-group difference. One-tailed z-tests are used in Panel A, and two-tailed z-tests are used in Panel B. The following abbreviations are used: $\mathrm{G}=$ Group payoffs displayed; $\mathrm{N}=$ group payoffs Not displayed; $\mathrm{I}=\mathrm{In}$-group; $\mathrm{O}=$ Out-group; $\mathrm{T}=$ Trust game; $\mathrm{D}=$ Dictator game.

RESULT 5: Second movers return more to first movers than dictators to passive participants when controlling for the level of transfer/endowment and group identity.

Support. As shown in Panel A of Table 11, all p-values are below the $1 \%$ level of statistical significance when controlling for the level of transfer/endowment and group identity.

Our fifth result thus, corroborates earlier findings, which, also, demonstrate that allocation choices are influenced by the process leading up to the available choices. A natural 
question to ask next is whether the extent of reciprocation differs when the first mover is an in-group versus an out-group participant. In Panel B of Table 11, we conduct a difference in difference test to determine whether the in-group difference is different from the out-group difference. Crucially, we find that the extent of reciprocation depends on the identity of the first mover, only, when group payoffs are displayed. In other words, in the baseline, second movers 'return' statistically similar amounts to first movers regardless of group identity.

\section{Concluding Remarks}

We have reported findings from laboratory experiments, in a near-minimal group setting, that investigate the effect on individual behavior of comparative information. In each round, group members could see the groups' cumulative payoffs, which consisted of an aggregation of the earnings of each member of the group in the round. Crucially, the group payoffs had no effect on agents' earnings, but provided, in an indirect way, information on other players' behavior.

We hypothesized and confirmed that the display of comparative, but payoff-irrelevant, information is sufficient to invoke an in-group bias in both games (RESULT 1). ${ }^{17}$ Thus, a link between the group members' payoffs and the group's behavior relative to that of the other group (as, for instance, in Bornstein, Gneezy, and Nagel (2002)) is not a necessary condition for an in-group bias. Yet the observed behavioral differences could be explained by mere categorization of subjects into groups rather than the per se effect of the display. To test this hypothesis, we conducted additional experiments where no comparative information was displayed. Our findings showed that mere categorization of subjects into groups is not sufficient to invoke an in-group bias (RESULT 2) in contrast to the prediction of the Social Identity Theory. Another plausible explanation could be that the display strengthened the psychological ties amongst in-group members and, thus, amplified in-group members' sense of group identity. Similar to Yamagishi and Kiyonari (2000), we measured participants' group attachment. If the display of group payoffs had a substantial effect on group identity, these measures of attachment should register a significant increase when group payoffs were displayed. We did not find this effect to be significant (RESULT 3). Based on the aforementioned results, we conjecture that the display acts as a public signal that makes groups salient; in turn, such group-based information saliency induces an in-group bias. In

\footnotetext{
${ }^{17} \mathrm{An}$ interesting direction for future research would be to test whether the display of comparative, but payoff-irrelevant, information is, also, necessary to establish an in-group bias.
} 
the future, further research should be undertaken to understand the cognitive mechanisms that might induce an in-group bias in group settings. Such mechanisms are likely to be important in explaining success and persistence or failure of social groups. Furthermore, we corroborated earlier results, which indicate that the display of comparative information is welfare reducing. More specifically, the display of group payoffs, relative to the baseline, induced first movers to transfer significantly less to out-group second movers, but did not induce them to transfer significantly more to in-group second movers, thus, resulting to a reduction in the total welfare (RESULT 4).

Finally, our choice of the Trust game and the Dictator game along with the carefullychosen payments of the options made possible a cross-game comparison to investigate any behavioral differences when the allocator decided on the split. When comparing the allocators' decisions across the two games, we found that a first mover's trust was reciprocated by the second mover independently of group identity when controlling for the level of transfer/endowment (RESULT 5). In addition, the extent of reciprocation was found to be conditioned on the identity of the first mover, only, when group payoffs were displayed. 


\section{References}

Berg, Joyce, John Dickhaut, and Kevin McCabe. "Trust, Reciprocity, and Social History." Games and Economic Behavior 10: (1995) 122-42.

Bernhard, Helen, Ernst Fehr, and Urs Fischbacher. "Group Affiliation and Altruistic Norm Enforcement." American Economic Review, 96, 2: (2006) 217-21.

Bohnet, Iris, and Richard J. Zeckhauser. "Social Comparison in Ultimatum Games." Scandinavian Journal of Economics 106, 3: (2004) 495-510.

Bornstein, Gary, Ido Erev, and Orna Rosen. "Intergroup Competition as a Structural Solution to Social Dilemmas." Social Behavior 5, 4: (1990) 247-60.

Bornstein, Gary, Uri Gneezy, and Rosemarie Nagel. "The Effect of Intergroup Competition on Intragroup Coordination: An Experimental Study." Games and Economic Behavior 41: (2002) 1-25.

Brown-Kruse, Jamie, and David Hummels. "Gender Effects in Laboratory Public Goods Contribution: Do Individuals Put Their Money Where Their Mouth Is?" Journal of Economic Behavior and Organization, 22, 3: (1993) 255-67.

Cadsby, Bram, and Elizabeth Maynes. "Gender and Free Riding in a Threshold Public Goods Game: Experimental Evidence." Journal of Economic Behavior and Organization 34, 4: (1998) 603-20.

Cason, Timothy N., and Vai-Lam Mui. "Social Influence in the Sequential Dictator Game." Journal of Mathematical Psychology 42: (1998) 248-65.

Charness, Gary, Luca Rigotti, and Aldo Rustichini. "Individual Behavior and Group Membership." American Economic Review, 97, 4: (2007) 1340-52.

Chen, Roy, and Yan Chen. "The Potential of Social Identity for Equilibrium Selection." American Economic Review 101: (2011) 2562-89.

Chen, Yan, Maxwell F. Harper, Joseph Konstan, and Sherry Xin Li. "Social Comparisons and Contributions to Online Communities: A Field Experiment on MovieLens." American Economic Review 100, 4: (2010) 1358-98.

Chen, Yan, and Sherry Xin Li. "Group Identity and Social Preferences." American Economic Review, 99, 1: (2009) 431-57. 
Duffy, John, and Nick Feltovich. "Does Observation of Others Affect Learning in Strategic Environments." International Journal of Game Theory 28, 1: (1999) 131-152.

Duffy, John, and Tatiana Kornienko. "Does Competition Affect Giving." Journal of Economic Behavior and Organization 74: (2010) 82-103.

Eckel, Catherine C., and Philip J. Grossman. "Managing Diversity by Creating Team Identity." Journal of Economic Behavior and Organization 58, 3: (2005) 371-92.

Eckel, Catherine C., and Rick K. Wilson. "Social Learning in Coordination Games: Does Status Matter?" Experimental Economics 10, 3: (2007) 317-29.

Erev, Ido, and Gary Bornstein. "The Enhancing Effect of Intergroup Competition on Group Performance." International Journal of Conflict Management 5: (1994) 271-84.

Erev, Ido, Gary Bornstein, and Rachely Galili. "Constructive Intergroup Competition as a Solution to the Free Rider Problem in the Workplace." Journal of Experimental Social Psychology 29: (1993) 463-78.

Fischbacher, Urs. "z-Tree: Zurich Toolbox for Ready-Made Economic Experiments." Journal of Experimental Economics, 10, 2: (2007) 171-78.

Forsythe, Robert, Joel L. Horowitz, N.E. Savin, and Martin Sefton. "Fairness in Simple Bargaining Experiments." Games and Economic Behavior 6, 3: (1994) 347-69.

Frey, Bruno S., and Stephan Meier. "Social Comparison and Pro-Social Behavior - Testing 'Conditional Cooperation' in a Field Experiment." American Economic Review 94, 5: (2004) 1717-22.

Goette, Lorenz, David Huffman, and Stephan Meier. "The Impact of Group Membership on Cooperation and Norm Enforcement: Evidence Using Random Assignment to Real Social Groups." American Economic Review 96, 2: (2006) 212-16.

Goette, Lorenz, David Huffman, Stephan Meier, and Matthias Sutter. "Competition between Organizational Groups: Its Impact on Altruistic and Anti-Social Motivations." Management Science 58, 5: (2012) 948-60.

Hargreaves Heap, Shaun P., and Daniel John Zizzo. "The Value of Groups." American Economic Review, 99, 1: (2009) 295-323.

Krupka, Erin, and Roberto Weber. "The Focusing and Informational Effects of Norms on Pro-Social Behavior." Journal of Economic Psychology 30, 3: (2009) 307-20. 
Nalbantian, Haig R., and Andrew Schotter. "Productibity Under Group Incentives: An Experimental Study." American Economic Review 87, 3: (1997) 314-41.

Shang, Jen, and Rachel Croson. "Field Experiments in Charitable Contributions: The Impact of Social Influence on the Voluntary Provision of Public Goods." Economic Journal 119: (2009) 1422-39.

Tajfel, Henry, and John Turner. "The Social Identity Theory of Intergroup Behavior." The Psychology of Intergroup Relations, ed. Stephen Worchel and William Austin, Chicago, IL: Nelson-Hall: (1986) 7-24.

Yamagishi, Toshio, and Toko Kiyonari. "The Group as the Container of Generalized Reciprocity." Social Psychology Quarterly, 63, 2: (2000) 116-32. 


\section{A Experimental Instructions}

This is an experiment on decision making. The amount of money you earn will depend upon the decisions you make and the decisions other people make. Your cumulative earnings in quarters ( 1 quarter $=25$ cents) will be the sum of your earnings from each round. At the end of the experimental session, you will be paid in cash your cumulative earnings. In addition, you will be paid a $\$ 10$ participation fee. Everyone will be paid in private and you are under no obligation to tell others how much money you earned. Please do not communicate with each other during the experiment. If you have a question, feel free to raise your hand, and an experimenter will come to help you. The experimental session has 3 parts and 16 participants.

\section{A.1 Group Assignment Stage}

A slide of colored dots will be shown and you will be asked to provide an estimate on the number of dots. Based on the similarity of your estimate with those of the other participants, you will be placed in either Group A or Group B. Eight of you will be placed in Group A and eight will be placed in Group B. The group identity will be retained for the entire experimental session.

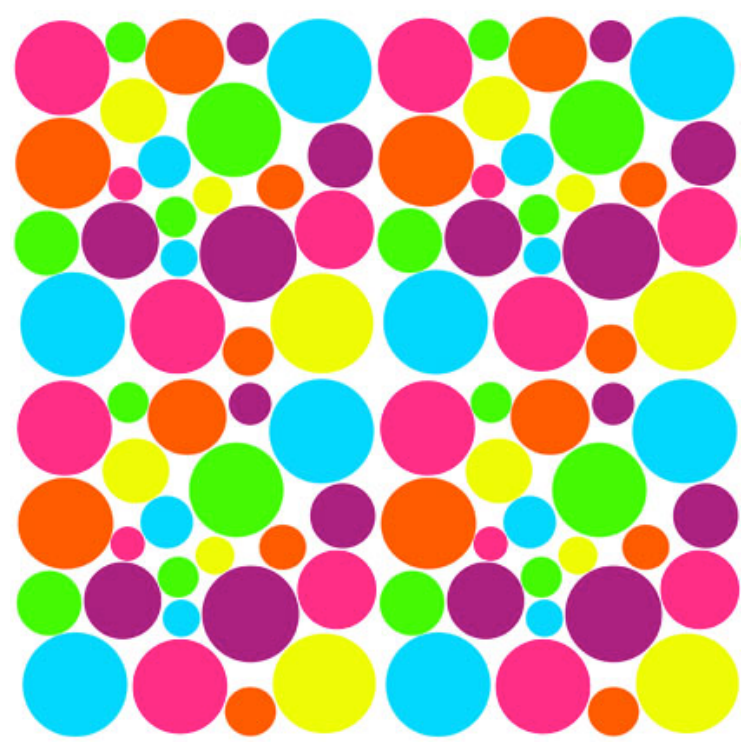

Figure 1: Dots 


\section{A.2 Game Play Stage}

\section{A.2.1 Trust Game [Group Payoffs Displayed]}

In the beginning of each round, you are matched with one other participant in the room. You will know whether the other participant is in-group (member of your own group) or outgroup (member of the other group), but you will not know any other information pertaining to the other participant. In every round you will be matched with different participants of the same group membership or of different group membership. You will never be matched with the same participant twice.

Initially, your role as the first mover or as the second mover is decided by chance. In other words, you are equally likely to be selected as the first mover or as the second mover in a given round. The first mover will make a decision and then the second mover will make a decision. In the beginning of a round, the first mover is endowed with 4 quarters. The first mover has to decide on how many quarters to transfer ( 0 or 1 or 2 or 3 or 4 ) to the second mover. The first mover keeps the quarters that he/she does not transfer to the second mover. The quarters that are transferred to the second mover are multiplied by a factor of 4; henceforth, this is referred to as the new amount. Then, the second mover decides on how many quarters of the new amount to keep, while the remainder goes to the first mover. Depending on the transfer of the first mover, the second mover's choices of Amount Kept are shown in the next page. The appropriate screen can only be one of the following screens. This completes one round.

The profit of the second mover for the round is simply the quarters he/she kept from the new amount. The profit of the first mover is the quarters he/she chose to hold on to (and not transfer to the second mover) plus any quarters the second mover did not keep from the new amount. At the end of each round, your earnings for the specific round are indicated as well as your cumulative earnings so far in the game. [In addition, the earnings of each Group for the specific round will be indicated. The earnings of each Group comprise of the earnings of each member of the Group summed together.] 


\section{A.2.2 Dictator Game [Group Payoffs Displayed]}

In the beginning of each round, you are matched with one other participant in the room. You will know whether the other participant is in-group (member of your own group) or outgroup (member of the other group), but you will not know any other information pertaining to the other participant. In every round you will be matched with different participants of the same group membership or of different group membership. You will never be matched with the same participant twice.

Initially, you will be assigned to either an active role or a passive role by chance. In other words, you are equally likely to be an active participant or a passive participant in a given round. The active participant will be the only one making a decision in a given round. In the beginning of a round, the participant with the active role is endowed with a number of quarters ( 7 or 10 or 13 or 16 quarters). The number of endowed quarters is decided by chance, and, therefore, can vary from person to person and from round to round. The active participant has to decide on how many quarters to keep, while the remainder goes to the passive participant. Depending on the endowment, the active participant's choices of Amount Kept are shown in the next page. The appropriate screen can only be one of the following screens. This completes one round.

The profit of the active participant for the round is the quarters he/she kept from the endowment. The profit of the passive participant for the round is the quarters the active participant did not keep from the endowment. At the end of each round, your earnings for the specific round are indicated as well as your cumulative earnings so far in the game. [In addition, the earnings of each Group for the specific round will be indicated. The earnings of each Group comprise of the earnings of each member of the Group summed together.] 


\section{A.3 Questionnaire}

1. What is your age?

2. What is your gender?
(a) Male
(b) Female

3. How many siblings do you have?
(a) 0
(b) 1
(c) 2
(d) 3

4. What do you consider your racial background?
(a) White
(b) Black
(c) Hispanic
(d) Asian
(e) Other

5. In the past twelve months, have you donated money to charities or done volunteer work for charitable causes or for nonprofit organizations?
(a) Yes
(b) No

6. What is your major?

7. Are you an undergraduate or graduate student?

(a) Undergraduate

(b) Graduate 
8. Which year are you in the program?
(a) 1
(b) 2
(c) 3
(d) 4

9. You were assigned to which Group?
(a) Group A
(b) Group B

10. On a scale from 1 to 10, please rate how closely attached you felt to the members of your own group throughout the experiment.

11. On a scale from 1 to 10, please rate how much commonality you felt you shared with the members of your own group throughout the experiment.

12. On a scale from 1 to 10, please rate how strong was the feeling of belongingness to the members of your own group throughout the experiment.

13. On a scale from 1 to 10, please rate your liking to the members of your own group throughout the experiment.

14. On a scale from 1 to 10, please rate how closely attached you felt to the members of the other group throughout the experiment.

15. On a scale from 1 to 10, please rate how much commonality you felt you shared with the members of the other group throughout the experiment.

16. On a scale from 1 to 10, please rate how strong was the feeling of belongingness to the members of the other group throughout the experiment.

17. On a scale from 1 to 10, please rate your liking to the members of the other group throughout the experiment. 
18. Were your decisions affected in any way by the group your match came from?
(a) Yes
(b) No

[19. Were your decisions affected in any way by the display of the cumulative earnings of the groups?]
(a) Yes
(b) No

20. Please tell us how your match's group membership affected your decision. Compared with having a match from the other group, if I was matched with someone from my own group:
(a) I was more likely to choose an equal payoff.
(b) I was more likely to earn as much as possible.
(c) I was more likely to earn more money than my match. 